\title{
Silício e imidacloprid na colonização de plantas por Myzus persicae e no desenvolvimento vegetativo de batata inglesa
}

\author{
Silicon and imidacloprid on plants colonized by Myzus persicae and on vegetative \\ development of potato
}

Flávia Batista Gomes ${ }^{{ }^{*}}$ Jair Campos Moraes ${ }^{\mathrm{I}}$ Gleice Aparecida Assis ${ }^{\mathrm{I}}$

RESUMO

O pulgão Myzus persicae (Sulzer) é considerado praga-chave da cultura da batata inglesa, cuja produtividade depende do uso de inseticidas para o seu controle. Este trabalho foi conduzido para verificar o efeito do silício e do imidaclopride na colonização de plantas por $\boldsymbol{M}$. persicae e seus possíveis reflexos positivos no desenvolvimento da batata inglesa. Foram testados cinco tratamentos, com sete repetições: 1- testemunha; 2- ácido silícico a 1\%; 3- imidacloprid na dosagem recomendada (252g ha-1); 4- ácido silícico a $1 \%$ e imidacloprid na metade da dosagem recomendada (126g ha-1); e 5imidaclopride na metade da dosagem recomendada (126g $\mathrm{ha}^{-1}$ ). Após 20 dias do plantio, as plantas (cv. Emeraude) foram infestadas com dez pulgões adultos. Avaliaram-se, após 20 dias da infestação, o número de ninfas e de adultos de pulgões, a altura, o diâmetro, o número de folhas e a fitomassa fresca $e$ seca das plantas. As plantas tratadas com o inseticida foram pouco colonizadas pelos pulgões e aquelas tratadas com silício apresentaram menor infestação em relação à testemunha. Em relação à altura, ao diâmetro e à fitomassa, não houve diferença significativa entre os tratamentos, porém a testemunha apresentou menor número de folhas. Assim, o silício diminuiu a colonização da batata por M. persicae e o uso da metade da dosagem recomendada de imidacloprid (126 $\left.\mathrm{g} \mathrm{ha}^{-1}\right)$ foi igualmente eficiente para impedir a colonização, tornando a adubação silicatada mais uma tática a ser testada no manejo integrado de pragas da batateira.

Palavras-chave: ácido silícico, Hemiptera, Aphididae, controle químico, neonicotinóide, resistência de plantas.

\section{ABSTRACT}

The aphid Myzus persicae (Sulzer) is a key pest of potato crops, the yield of which depends on insecticides for its control. This research was carried out to verify the effect of silicon and imidacloprid on the colonization of potato plants by $\mathbf{M}$. persicae and its possible positive consequences on development parameters. Five treatments with seven replications were tested: 1-control treatment; 2- 1\% silicic acid; 3imidacloprid at the recommended dosage (252g ha-1); 4- 1\% silicic acid and imidacloprid at half recommended dosage (126 $\left.\mathrm{g} \mathrm{ha}^{-1}\right)$ and 5- imidacloprid at half the recommended dosage (126g ha $\left.\mathrm{g}^{-1}\right)$. Twenty days after planting, the plants were infested with ten adult aphids. After 20 days of infestation, the number of nymphs and of adult aphids; the height, the diameter, the number of leaves and the fresh and dried weights of the plants were evaluated. The plants treated with insecticides were not so colonized by the aphids and those with silicon presented lower infestation in relation to the control. In relation to the height, diameter and weights, there was no significant difference among the treatments, however the control presented the lowest number of leaves. Therefore, silicon reduced the colonization of potato by M. persicae and the use of half dosage of imidacloprid (126 $\mathrm{g} \mathrm{h}^{-1}$ ) was equally efficient to prevent the colonization, making silicated fertilization one more strategy to be tested in the integrated management of potato plant pests.

Key words: silicic acid, Hemiptera, Aphididae, chemical control, neonicotinoid, plant resistance.

\section{INTRODUÇÃO}

O pulgão Myzus persicae (Sulzer) é uma espécie polífaga, mundialmente distribuída, que possui mais de 500 espécies de plantas hospedeiras, incluindo muitas culturas de importância agrícola (BLACKMAN \& EASTOP, 2000). Entre essas culturas, destaca-se a batata inglesa, solanácea que é uma das hortaliças mais cultivadas e consumidas no mundo e de grande importância econômica para o Brasil e para Minas Gerais, responsável pela maior produção do país, que

IDepartamento de Entomologia, Universidade Federal de Lavras (UFLA), CP 3037, 37200-000, Lavras, MG, Brasil. E-mail: fg.batista@bol.com.br.*Autor para correspondência. 
foi de 981 mil toneladas em 2006 (AGRIANUAL, 2007). O cultivo de batata inglesa nos trópicos é um dos que mais sofre com problemas fitossanitários. Além dos danos diretos causados pela sucção contínua de seiva, M. persicae é considerado o mais importante vetor de PLRV (Potato leafroll virus) e do PVY (Potato virus Y) (LARA et al., 2004).

Além do alto custo dos inseticidas que onera o custo de produção, o uso intensivo desses produtos fitossanitários no controle de pulgões, desde 1950, tem levado ao desenvolvimento de vários mecanismos de resistência dos insetos aos principais grupos de inseticidas (DEVONSHIRE et al., 1998). Contudo, inseticidas neonicotinóides, um grupo desenvolvido recentemente, são efetivos contra $\boldsymbol{M}$. persicae (FOSTER et al., 2003). Imidacloprid é um inseticida do grupo dos neonicotinóides, registrado em mais de 70 países para aplicação foliar, via solo, e também para tratamento de sementes (NAUEN et al., 1998).

O silício é um nutriente vegetal que não preenche todos os critérios a partir dos quais um elemento químico é considerado essencial para as plantas e, assim, é considerado um elemento benéfico ou útil às plantas (NOJOSA et al., 2006). O silício é encontrado na solução do solo e é absorvido pelas plantas como ácido silícico, transportado por meio do xilema e depositado como sílica amorfa ou também pode formar estruturas silicificadas, os fitólitos (RAVEN, 2001).

Entre as respostas ao fornecimento de silício, destacam-se a diminuição do acamamento, o aumento da resistência ao estresse hídrico, os ganhos de produtividade e o aumento da resistência das plantas ao ataque de pragas e doenças (NOJOSA et al., 2006).

O presente trabalho objetivou avaliar o efeito da aplicação do silício e do inseticida imidaclopride, isoladamente ou em associação, na colonização de plantas pelo pulgão $\boldsymbol{M}$. persicae e seus possíveis reflexos positivos no desenvolvimento vegetativo da batata inglesa.

\section{MATERIAL E MÉTODOS}

O experimento foi realizado em condições de casa de vegetação no período de dezembro de 2006 a janeiro de 2007.

Foi plantada uma batata-semente, cultivar Emeraude, em vaso com capacidade para $2 \mathrm{~kg}$ de substrato (latossolo vermelho-escuro). A adubação foi feita de acordo com a preconizada para a cultura (MALAVOLTA, 1980), mediante análise de solo. As plantas foram cultivadas em uma gaiola confeccionada de tecido organza com as seguintes dimensões: $3 \mathrm{~m}$ de comprimento, $1 \mathrm{~m}$ de altura e $1 \mathrm{~m}$ de largura. Essa gaiola foi mantida em casa de vegetação. A umidade foi mantida por meio de irrigação conforme a necessidade do solo. Os pulgões $\boldsymbol{M}$. persicae foram criados em plantas de pimentão, em sala climatizada, com temperatura de $25 \pm 2^{\circ} \mathrm{C}$ e fotofase de 12 horas.

Foram testados cinco tratamentos: 1testemunha; 2- adubação via solo com 200mL de solução de ácido silícico a 1\%; 3- aplicação via solo de 0,252mg de imidacloprid, diluídos em 200mL de água; 4-adubação via solo com 200mL de solução de ácido silícico a 1\% e 0,126mg de imidacloprid, diluídos em 200mL de água; e 5- aplicação via solo de 0,126mg de imidaclopride, diluídos em 200mL de água. Os produtos, depois de diluídos, foram aplicados diretamente no solo, ao redor das hastes das plantas. Na testemunha foram aplicados $200 \mathrm{~mL}$ de água. Os tratamentos foram aplicados após a emergência das hastes, uma semana após o plantio da batata-semente.

Após 20 dias da aplicação dos tratamentos as plantas foram desbastadas, deixando-se apenas uma haste por vaso e, em seguida, foram infestadas com dez pulgões adultos. As avaliações foram feitas 20 dias após a liberação dos pulgões, pela contagem de pulgões adultos e de ninfas presentes em cada haste.

Foram realizadas aferições de altura, diâmetro, fitomassa fresca e seca das hastes e número de folhas por haste. A altura foi medida com uma trena e o diâmetro, com paquímetro, e ambos foram expressos em cm. Para determinação da fitomassa fresca, as plantas foram cortadas rente ao solo, colocadas em sacos de papel e pesadas. Em seguida, as plantas foram colocadas em estufa a $60^{\circ} \mathrm{C}$ até peso constante e pesadas novamente para a determinação da fitomassa seca. As fitomassas foram expressas em $\mathrm{g}$.

Foi utilizado o delineamento experimental inteiramente ao acaso, com cinco tratamentos e sete repetições. Cada parcela foi representada por uma planta. Os dados obtidos foram submetidos à análise de variância e as médias foram comparadas pelo teste de SCOTT \& KNOTT (1974) a 5\% de significância, sendo que os dados de contagem foram transformados $\operatorname{para} \sqrt{X+0,5}$.

\section{RESULTADOS E DISCUSSÃO}

Em relação ao número de ninfas presentes em cada planta, foram observadas diferenças entre os tratamentos (Tabela 1). A testemunha apresentou um número maior de ninfas que os demais tratamentos (220,9 por haste). Foram encontradas, neste tratamento, mais que o dobro de ninfas nas plantas adubadas com silício (94,6 ninfas por haste). Nas plantas com aplicação 
Tabela 1 - Número de ninfas e adultos (média \pm erro padrão) de pulgões $\boldsymbol{M}$. persicae em plantas de batata inglesa tratadas com silício e imidacloprid. Lavras, MG. 2007.

\begin{tabular}{lcc}
\hline Tratamento & $\mathrm{N}^{\mathrm{o}}$ ninfas por haste & $\mathrm{N}^{\mathrm{0}}$ adultos por haste \\
\hline Testemunha & $220,9 \pm 27,39 \mathrm{a}$ & $31,1 \pm 2,90 \mathrm{a}$ \\
Silício $\left(2 \mathrm{t} \mathrm{ha}{ }^{-1}\right)$ & $94,6 \pm 9,22 \mathrm{~b}$ & $26,1 \pm 4,49 \mathrm{a}$ \\
Imidacloprid $\left(252 \mathrm{~g} \mathrm{ha}^{-1}\right)$ & $0,7 \pm 0,14 \mathrm{c}$ & $0,4 \pm 0,11 \mathrm{~b}$ \\
Silí́cio $\left(2 \mathrm{t} \mathrm{ha}{ }^{-1}\right)+\mathrm{Imidacloprid}_{\left(126 \mathrm{~g} \mathrm{ha}^{-1}\right)}$ & $0,0 \pm 0,00 \mathrm{c}$ & $0,0 \pm 0,00 \mathrm{~b}$ \\
Imidacloprid $\left(126 \mathrm{~g} \mathrm{ha}^{-1}\right)$ & $0,3 \pm 0,07 \mathrm{c}$ & $0,8 \pm 0,17 \mathrm{~b}$ \\
& & 2,50 \\
Média geral & 5,06 & 60,99 \\
\hline
\end{tabular}

Médias não seguidas de mesma letra na coluna diferem significativamente entre si pelo teste de Scott \& Knott em nível de 5\% de significância.

de imidacloprid, na dose recomendada ou em metade desta dose, o número de ninfas foi quase nulo. Para o número de adultos, não foram observadas diferenças entre os tratamentos testemunha e o com silício, sendo de 31,1 e 26,1, respectivamente. Os tratamentos com o inseticida imidacloprid apresentaram reduzido número de adultos.

O menor número de ninfas nas plantas com silício em relação às plantas não tratadas pode ser devido ao efeito desse elemento na fecundidade dos pulgões e/ou na mortalidade direta de ninfas. Em trigo, COSTA \& MORAES (2006) também observaram que a aplicação de silício diminuiu o número de ninfas colocadas por Schizaphis graminum (Rond.) em até $80 \%$ e a taxa de crescimento populacional $\left(\mathrm{r}_{\mathrm{m}}\right)$, em torno de 25\%. Já CORREA et al. (2005) observaram o efeito negativo da adubação com silício via solo e/ou via foliar na sobrevivência ninfal de Bemisia tabaci (Genn.) biótipo B em plantas de pepino.

A qualidade nutricional da planta hospedeira pode afetar diretamente a fecundidade de insetos herbívoros em escala individual e populacional, sendo que a qualidade nutricional está relacionada com os teores de carbono e nitrogênio presente nas plantas e também com metabólitos secundários tóxicos ou deterrentes aos herbívoros (AWMACK \& LEATHER, 2002; BIALCZYK et al., 1999). É provável que o silício tenha atuado como indutor da síntese de compostos de defesa nas plantas, como os taninos e/ou outras moléculas defensivas (GOMES et al., 2005).

Todavia, não foi observado efeito conjunto do silício com o inseticida imidacloprid, como a interação inseticida lufenuron e silício para Spodoptera frugiperda (J.E. Smith) (NERI et al., 2005). A ausência de pulgões nas plantas, mesmo com a metade da dose do inseticida, pode ser devida ao efeito letal do imidacloprid (FOSTER et al., 2003) ou à sua ação como fagodeterrente, que afeta a movimentação e o comportamento alimentar de pulgões, particularmente em concentrações subletais (NAUEN, 1995; BOITEAU \& OSBORN, 1997). Além do controle de $\boldsymbol{M}$. persicae, a utilização de baixa dosagem de imidacloprid pode ser eficiente na prevenção de transmissão do PLRV (MOWRY \& OPHUS, 2002; MOWRY, 2005).

A possibilidade de redução da dose de inseticida no controle de insetos-praga proporcionaria inúmeros benefícios, principalmente a diminuição do gasto com inseticidas que, no Brasil, representa $13 \%$ do custo de produção de batata inglesa (AGRIANUAL, 2007). Além disso, contribuiria para o manejo da resistência de insetos a inseticidas, que é um dos grandes entraves em programas de controle de pragas envolvendo o uso de produtos químicos.

Não foram observadas diferenças entre os tratamentos testados em relação à altura e ao diâmetro das plantas de batata inglesa (Tabela 2). Entretanto, as plantas testemunha apresentaram menor número de folhas em relação aos demais tratamentos. Também não foi observada diferença entre os tratamentos em relação à fitomassa fresca e seca das plantas (Tabela 3).

As folhas constituem a parte mais importante da planta com relação à quantidade de CO fixada pela fotossíntese, um processo fisiológico quę resulta no acúmulo de matéria seca (RITCHIE et al., 1994). Assim, o crescimento e o desenvolvimento das plantas podem ser aferidos pela quantidade de matéria seca acumulada pela planta. A produção de matéria seca está diretamente relacionada com a quantidade de luz absorvida e aumenta à medida que a área foliar também aumenta. Entretanto, a quantidade de matéria seca produzida depende não somente da quantidade 
Tabela 2 - Altura, diâmetro e número de folhas (média \pm erro padrão) de plantas de batata inglesa tra tadas com silício e imidacloprid. Lavras, MG. 2007.

\begin{tabular}{lccc}
\hline Tratamento & Altura (cm) NS* & Diâmetro (cm) NS* & $\mathrm{N}^{\mathrm{o}}$ de folhas ** \\
\hline Testemunha & $12,2 \pm 0,53$ & $0,7 \pm 0,02$ & $11,0 \pm 0,62 \mathrm{~b}$ \\
Silício $\left(2 \mathrm{t} \mathrm{ha}^{-1}\right)$ & $12,9 \pm 0,31$ & $0,7 \pm 0,01$ & $15,1 \pm 0,32 \mathrm{a}$ \\
Imidacloprid $\left(252 \mathrm{~g} \mathrm{ha}^{-1}\right)$ & $13,6 \pm 0,55$ & $0,6 \pm 0,02$ & $14,0 \pm 0,39 \mathrm{a}$ \\
Silício $\left(2 \mathrm{t} \mathrm{ha}^{-1}\right)+\mathrm{Imidacloprid}\left(126 \mathrm{~g} \mathrm{ha}^{-1}\right)$ & $15,6 \pm 0,39$ & $0,8 \pm 0,01$ & $16,1 \pm 0,22 \mathrm{a}$ \\
Imidacloprid $\left(126 \mathrm{~g} \mathrm{ha}^{-1}\right)$ & $15,0 \pm 0,44$ & $0,7 \pm 0,01$ & $15,0 \pm 0,44 \mathrm{a}$ \\
& & 0,68 & 14,26 \\
Média geral & 13,87 & 20,64 \\
\hline
\end{tabular}

*NS: não significativo.

**Médias não seguidas de mesma letra na coluna diferem significativamente entre si pelo teste de Scott \& Knott em nível de 5\% de significância.

de radiação recebida pela planta, mas também da eficiência na utilização dessa energia (SHIBLES \& WEBER, 1966). Dessa forma, pode-se concluir que aumento da área foliar nem sempre significa aumento na quantidade de matéria seca produzida pelas plantas.

O silício acumula nos tecidos de suporte e sustentação do caule, fortalecendo substancialmente a estrutura da planta (PLUCKNETT, 1971). Porém, este efeito não foi observado nas plantas de batata inglesa porque não houve aumento no diâmetro das hastes. Entre os benéficos relacionados à adubação silicatada, podem ser mencionados o aumento da fitomassa seca da parte aérea e das raízes e a importância do silício para o crescimento e desenvolvimento das plantas (EPSTEIN, 1994). Entretanto, a aplicação de ácido silícico não influenciou o tamanho, o diâmetro e a fitomassa seca das plantas de batateira, mas aumentou o número de folhas de maneira semelhante ao inseticida imidacloprid, possivelmente devido a alguma alteração no metabolismo das plantas, fato que deve ser investigado em outras pesquisas. Em milho também não se observaram aumentos no tamanho e na fitomassa fresca das plantas adubadas com silício, porém observou-se maior diâmetro do caule de plantas tratadas com silício (NERI, 2006).

\section{CONCLUSÕES}

O silício é um elemento mineral capaz de diminuir a colonização das plantas de batata pelo pulgão M. persicae. A utilização de $126 \mathrm{gha}^{-1}$ imidacloprid (na metade da dosagem recomendada) impede a colonização por M. persicae em plantas de batata.

\section{AGRADECIMENTOS}

Ao Conselho Nacional de Desenvolvimento Científico e Tecnológico (CNPq) e à Coordenação de Aperfeiçoamento de Pessoal de Nível Superior (CAPES), pela concessão de bolsas e à Fundação de Amparo à Pesquisa de Minas Gerais (FAPEMIG), pelo apoio financeiro ao projeto.

Tabela 3 - Fitomassa fresca e seca (média \pm erro padrão) de plantas de batata inglesa tratadas com silício e imidacloprid. Lavras, MG. 2007.

\begin{tabular}{lcc}
\hline Tratamento & Fitomassa fresca (g) NS* & Fitomassa seca (g) NS* \\
\hline Testemunha & $16,2 \pm 1,04$ & $1,6 \pm 0,10$ \\
Silício $\left(2 \mathrm{t} \mathrm{ha}{ }^{-1}\right)$ & $14,6 \pm 0,71$ & $1,6 \pm 0,11$ \\
Imidacloprid $\left(252 \mathrm{~g} \mathrm{ha}^{-1}\right)$ & $15,3 \pm 0,72$ & $1,4 \pm 0,07$ \\
Silício $\left(2 \mathrm{t} \mathrm{ha} \mathrm{H}^{-1}+{\mathrm{Imidacloprid}\left(126 \mathrm{~g} \mathrm{ha}^{-1}\right)}^{\text {Imidacloprid }\left(126 \mathrm{~g} \mathrm{ha}^{-1}\right)}\right.$ & $21,0 \pm 0,63$ & $2,1 \pm 0,07$ \\
& $16,6 \pm 0,96$ & $1,7 \pm 0,10$ \\
Média geral & & 1,69 \\
CV (\%) & 16,75 & 42,54 \\
\hline
\end{tabular}

NS: não significativo. 


\section{REFERÊNCIAS}

AGRIANUAL 2007 - Anuário da Agricultura Brasileira. São Paulo: FNP Consultoria e Comércio, 2007. 516p.

AWMACK, C.S.; LEATHER, S.R. Host plant quality and fecundity in herbivorous insects. Annual Review of Entomology, Palo Alto, v.47, p.817-844, 2002.

BIALCZYK, J. et al. The protective action of tannins against glasshouse whitefly in tomato seedlings. Journal of Agricultural Science, Cambridge, v.133, n.2, p.197-201, 1999.

BLACKMAN, R.L.; EASTOP, V.F. Aphids on the world's crops. An indentification and information guide. 2.ed. Chichester: Wiley, 2000. 482p.

BOITEAU, G.; OSBORN, W.P.L. Behavioural effects of imidacloprid, a new nicotinyl insecticide, on the potato aphid, Macrosiphum euphorbiae (Thomas) (Homoptera, Aphididae). Canadian Entomologist, Ottawa, v.129, n.2, p.241-249, 1997.

CORREA, R.S.B. et al. Silicon and acibenzolar-S-methyl as resistance inducers in cucumber, against the whietfly Bemisia tabaci (Gennadius) (Hemiptera: Aleyrodidae) biotype B. Neotropical Entomology, Londrina, v.34, n.3, p.429-433, 2005.

COSTA, R.R.; MORAES, J.C. Efeitos do ácido silícico e do acibenzolar-s-methyl sobre Schizaphis graminum (Rondani) (Hemiptera: Aphididae) em plantas de trigo. Neotropical Entomology, Londrina, v.35, n.6, p.834-839, 2006.

DEVONSHIRE, A. et al. The evolution of insecticide resistance in the peach-potato aphid, Myzus persicae. Biological Sciences, Boulder, p.1677-1684, 1998.

EPSTEIN, E. The anomaly of silicon in plant biology. Proceedings National of Academy Science of the United State of America, Washington, v.91, n.1, p.11-17, 1994.

FOSTER, S.P et al. Variation in response to neonicotinoid insecticides in peach-potato aphids, Myzus persicae (Hemiptera: Aphididae). Pest Management Science, Sussex, v.59, n.2, p.166-173, 2003

GOMES, F.B. et al. Resistance induction in wheat plants by silicon and aphids. Scientia Agricola, Piracicaba, v.62, n.6, p.547-551, 2005.

LARA, F.M. et al. Resistência de genótipos de batata ao pulgão. Horticultura Brasileira, Brasília, v.22, n.4, p.775779, 2004

MALAVOLTA, E. Elementos de nutrição mineral de plantas. São Paulo: Ceres, 1980. 251p.
MOWRY, T.M. Insecticidal reduction of Potato leafroll vírus transmission by Myzus persicae. Annals of Apllied Biology, Warwick, v.146, n.1, p.81-88, 2005.

MOWRY, T.M.; OPHUS, J.D. Effects of sub-lethal imidacloprid levels on potato leafroll virus transmission by Myzus persicae. Entomologia Experimentalis et Applicata, Dordrecht, v.103, n.3, p.249-255, 2002.

NAUEN, R. Behaviour modifying effects of low systemic concentrations of imidacloprid on Myzus persicae with special reference to an antifeeding response. Pesticide Science, Sussex, v.44, n.2, p.145-153, 1995.

NAUEN, R. et al. Antifeedant effects of sublethal dosages of imidacloprid on Bemisia tabaci. Entomologia Experimentalis et Applicata, Dordrecht, v.88, n.3, p.287293, 1998.

NERI, D.K.P. Efeito do silício na resistência de plantas de milho a Rhopalosiphum maidis (Fich.) (Hemiptera: Aphididae) e sua interação com inseticida no controle de Spodoptera frugiperda (J. E. Smith) (Lepidoptera: Noctuidae). 2006. 68f. Tese (Doutorado em Entomologia) - Universidade Federal de Lavras, Lavras, MG.

NERI, D.K.P. et al. Interação silício com inseticida regulador de crescimento no manejo da lagarta-do-cartucho Spodoptera frugiperda (J. E. Smith, 1797) (Lepidoptera: Noctuidae) em milho. Ciência e Agrotecnologia, Lavras, v.29, n.6, p.11671174, 2005.

NOJOSA , G.B.A. et al. Uso de fosfitos e silicatos na indução de resistência. In: CAVALCANTI, L.S. et al. (Ed.). Indução de resistência em plantas a patógenos e insetos. Piracicaba: FEALQ, 2006. 263p.

PLUCKNETT, D.L. The use soluble silicates in Hawaii agriculture. University of Queensland, Hawaii, v.1, n.6, p.203-223, 1971.

RAVEN, J.A. Silicon transport at the cell and tissue level. In: DATNOFF, L.E. et al. (Ed.). Silicon in agriculture. The Netherlands: Elsevier Science, 2001. 403p.

RITCHIE, P.M. et al. How a soybean plants develops. Ames: Iowa State University of Science and Techonology, Cooperative Extension Service, 1994. 20p. (Special Report, 53).

SCOTT, A.J.; KNOTT, M.A. Acluster analysis method for gruping means in the analysis of varianicis. Biometrics, Washigton, v.30, n.3, p.507-512, 1974.

SHIBLES, R.M.; WEBER, C.R. Interception of solar radiation and dry matter production by various soybean planting patterns. Crop Science, v.6, n.1, p.55-59, 1966. 